\title{
Qualidade da Água Dessalinizada Destinada às Comunidades Rurais de Mossoró/ RN
}

Daianni Ariane da Costa Ferreira*(Mestranda em Manejo de Solo e Água na Universidade Federal Rural do Semi-Árido - UFERSA)

Ana Kaline da Costa Ferreira; (Doutoranda em Manejo de Solo e Água na Universidade Federal Rural do Semi-Árido - UFERSA)

Ana Cecília da Costa Sinclair Marinho; (Mestra em Manejo de Solo e Água na Universidade Federal

$$
\text { Rural do Semi-Árido - UFERSA) }
$$

Fernanda Lima Cavalcante; (Doutoranda em Manejo de Solo e Água na Universidade Federal Rural do

$$
\text { Semi-Árido - UFERSA) }
$$

Kaline Dantas Travassos; (Bolsista PDJ/CNPq na Universidade Federal Rural do Semi-Árido)

Ana Cláudia Medeiros Souza; (Doutoranda em Manejo de Solo e Água na Universidade Federal Rural do Semi-Árido - UFERSA)

* Email: daianniariane@ufersa.edu.br

\section{Resumo:}

A escassez da água, tanto em quantidade como em qualidade, no nordeste brasileiro, desencadeia o abalo no desenvolvimento socioeconômico e, até mesmo, à subsistência da população.

O objetivo deste trabalho foi avaliar a qualidade da água destinada às comunidades rurais de Mossoró, abastecidas com águas salobras provenientes de poços tubulares, dotados de dessalinizadores. O presente trabalho foi realizado em 11 comunidades rurais do município de Mossoró/RN, onde estavam instalados estações de tratamentos de água salobra pelo projeto água boa e água de beber dos governos Federal e Estadual. Em cada comunidade foram coletadas amostras de três tipos de água: água do poço (AP); água dessalinizada (AD) e água de rejeito da dessalinização (AR). Os parâmetros físico-químicos avaliados foram: condutividade elétrica (CE em dS $\left.\mathrm{m}^{-1}\right)$, potencial hidrogeniônico $(\mathrm{pH})$, as concentrações de Sódio $\left(\mathrm{Na}^{+}\right)$, Cálcio $\left(\mathrm{Ca}^{2+}\right)$, Magnésio $\left(\mathrm{Mg}^{2+}\right)$, Potássio $\left(\mathrm{K}^{+}\right)$, Cloreto $\left(\mathrm{Cl}^{-}\right)$e dureza, de acordo com as metodologias propostas por Richards (1954) e EMBRAPA (1997). Observou-se, de um modo geral, as instalações dos equipamentos de dessalinização trouxeram um enorme ganho na qualidade de vida das comunidades, pelo fato de representar uma ferramenta eficaz no fornecimento regular de água doce no período de estiagem do semiárido. As águas retiradas diretamente dos dessalinizadores apresentaram qualidades satisfatórias, quanto à remoção de íons, o que comprova sua eficiência na redução da salinidade. Contudo, não foi possível determinar o impacto exato desta melhoria na saúde da população estudada, devido à ausência em análises que comprovassem a isenção de uma contaminação bacteriológica. Os dados obtidos apontam que as águas dos poços e as águas de rejeito das comunidades rurais estudadas possuem restrições para a sua utilização na agricultura, por apresentarem elevadas concentrações de sais, favorecendo riscos de salinização e sodificação do solo.

\section{Palavras-chave:}

Escassez de água; dessalinizadores; parâmetros físico-químicos. 


\section{I ntrodução}

O semiárido nordestino brasileiro, historicamente, é afligido pela escassez de água, tanto em quantidade como em qualidade, constituindo um forte entrave ao desenvolvimento socioeconômico e, até mesmo, à subsistência da população.

Dentro desse contexto, a exploração das águas subterrâneas, a partir da perfuração de poços tubulares, se torna uma importante alternativa para o suprimento hídrico para as comunidades rurais do semiárido.

No município de Mossoró, geralmente, são utilizados poços rasos, perfurados no Calcário Jandaíra, com custo inferior aos perfurados no Arenito Açu, porém apresentam menores vazões e a água apresenta níveis de salinidade elevada, o que prejudica o uso destas águas para dessedentamento humano e animal ou para fins de irrigação (COSME, 2011).

Grande parte da região (788 mil km², ou 51\% da área total do Nordeste) está situada sobre rochas cristalinas e o contato por longo tempo, no subsolo, entre a água e esse tipo de rocha, leva a um processo de salinização (SOARES et al., 2006). Uma vez que a água entra em contato com as rochas cristalinas, geralmente, os teores de sólidos totais dissolvidos (STD) superam os $2.000 \mathrm{mg} \mathrm{L}^{-1}$, em $75 \%$ dos casos, correspondendo a uma quantidade duas vezes maior que os limites permitidos para o consumo humano (REBOUÇAS, 1999).

Como forma de mitigar este problema, os Governos Federal e Estadual desde meados da década de 1990 têm instalado equipamentos de dessalinização das águas salobras subterrâneas, objetivando a geração de água doce para o abastecimento de comunidades no Nordeste (ANDERS, 2013).

De acordo com a Companhia de Pesquisa de Recursos Minerais (CPRM MME, 2005), o município de Mossoró-RN apresenta 749 poços, dos quais 68 são destinados ao atendimento comunitário. No município, cerca de 50 comunidades rurais utilizam a água salobra proveniente do aqüífero situado no calcário da formação Jandaíra como fonte hídrica para abastecimento doméstico, de importância econômica e social na região, por causa da sua abrangência e pouca profundidade, com uma geologia que se caracteriza pela presença de rochas calcárias (carbonato de cálcio), o que contribui para a presença de água salobra e às vezes salina (ANDERS, 2013).

O método de dessalinização predominante nessa região é a osmose reversa por causa, principalmente, da sua simplicidade operacional, e do seu baixo custo.

A osmose é o movimento da água entre meios com concentrações diferentes de solutos, separados por uma membrana semipermeável. É um processo físico importante no metabolismo celular. Na osmose, a água movimenta-se sempre de um meio hipotônico (menos concentrado em soluto) para um meio hipertônico (mais concentrado em soluto) com o objetivo de se atingir um equilíbrio na concentração em ambos os meios (isotônicos) através de uma membrana semipermeável, ou seja, uma membrana cujos poros permitem a passagem de moléculas de água, mas impedem a passagem de outras moléculas. A osmose reversa é precisamente o processo inverso. Neste caso a água passará por uma membrana do sentido hipertônico para hipotônico. Para conseguir uma pressão superior à pressão osmótica recorre-se a uma bomba de alta pressão especialmente desenhada e revestida para o efeito. Conseguida essa pressão a água salgada é pressionada contra as membranas de modo a que o fenômeno, osmose reversa, aconteça (NETO et al., 2007).

Amorim et al. (2004) atribuem o predomínio da osmose reversa à simplicidade e robustez do equipamento, aos baixos custos de instalação e operação, incluindo o consumo de energia e de mãode-obra na operação, à capacidade de tratar volumes baixos a moderados de água bruta, à elevada taxa de recuperação, à continuidade do processo e à excelente qualidade da água tratada.

A água dessalinizada é potável, isenta de vírus, pirogênios, fungos e bactérias e atende a todos os padrões de potabilidade aprovados pela Organização Mundial de Saúde (NETO et al., 2007).

No entanto, a osmose reversa implica na geração de rejeito, uma água residuária do processo e que tem concentração iônica majorada, ou seja, ao se dessalinizar a água salobra, transformando-a em água doce, gera-se outro tipo de água, mais salina que a própria água salobra e, por conseguinte, com risco de contaminação ambiental elevado (SOARES et al., 2006).

Dependendo do equipamento e da qualidade da água do poço, a quantidade de rejeito gerado será da ordem de 40 a $70 \%$ do total de água salobra retirada do poço (PORTO et al., 2001). Esse rejeito necessita ser utilizado de forma ambientalmente correta, possibilitando sempre que possível à 
produção de alimentos, pois quase sempre os cursos d'água e o solo são os principais meios para sua deposição. Considerando o número de dessalinizadores na região do semiárido nordestino, estimado em torno de 400 equipamentos, um grande volume de rejeito está sendo gerado e na maioria dos casos, não está recebendo qualquer tratamento e, mesmo assim, está sendo despejado no solo ou nos corpos hídricos, propiciando a salinização dos solos e desertificação das áreas (PORTO et al., 2001).

O presente trabalho teve como objetivo avaliar a qualidade da água destinada às comunidades rurais de Mossoró, abastecidas com águas salobras provenientes de poços tubulares, dotados de dessalinizadores.

Como objetivos específicos têm-se:

- Avaliar parâmetros físico-químicos relacionados à presença de sais nas águas dessalinizadas destinadas às comunidades rurais de Mossoró;

- Relacionar os parâmetros físico-químicos obtidos com aqueles estabelecidos para as águas potáveis;

- Relacionar os parâmetros físico-químicos obtidos com aqueles estabelecidos para uso agrícola;

- Avaliar a eficiência dos dessalinizadores quanto á remoção de sais.

\section{Material e Métodos}

O trabalho foi realizado em comunidade rurais do município de Mossoró-RN, onde foram instalados estações de tratamentos de água salobra pelo projeto água boa e água de beber dos governos Federal e Estadual. O município de Mossoró situa-se na mesorregião Oeste Potiguar e na microrregião Mossoró. Abrange uma área de $2.100 \mathrm{~km}^{2}$ (Figura 1).

Inicialmente foram identificadas as comunidades rurais que tinham, por fonte de abastecimento hídrico, poços com água salobra com tratamento para consumo por meios da dessalinização, a partir dos cadastros na prefeitura do município.

Com base nas informações acerca da localização dos poços contidas no Cadastro de Fontes de Abastecimento por Água Subterrânea da Companhia de Pesquisa de Recursos Minerais (CPRM MME, 2005) e com o auxílio do software Google (2005) foram localizadas as comunidades rurais e, a partir daí foram selecionadas 11 comunidades, tendo como critério de seleção a facilidade de acesso (Figura $1)$.

Figura 1 - Mapa de localização das comunidades onde foram coletadas as amostras de água.

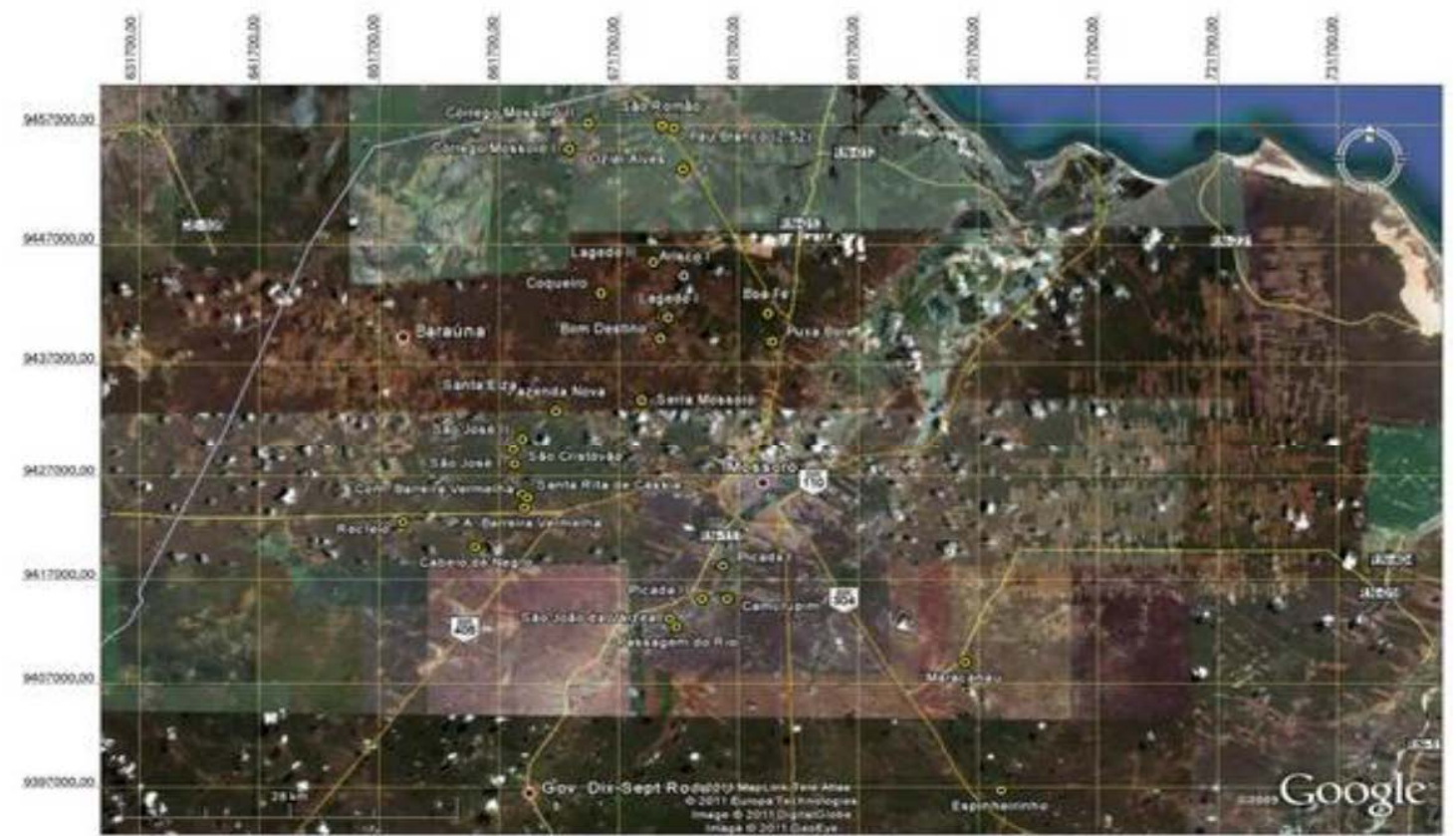

Fonte: Google Earth. 
As coletas de amostras foram realizadas no período de maio a junho de 2014 (Tabela 1).

Tabela 1 - Comunidades visitadas onde foram coletadas as amostras das águas para avaliação da qualidade.

$\begin{array}{lll}\text { Data da Visita } & \text { Comunidades } & \begin{array}{l}\text { Coordenada UTM do dessalinizador } \\ \text { Datum -WGS 84 / Zona UTM - 24 M }\end{array}\end{array}$

\begin{tabular}{llllll}
\hline \multirow{5}{*}{$16 / 05 / 2014$} & Boa Fé & E & 684075 & S & 9441345 \\
& Puxa Boi & E & 684435 & S & 9438886 \\
& Oziel Alves & E & 676973 & S & 9453487 \\
& São Romão & E & 675227 & S & 9457149 \\
& Córrego Mossoró I & E & 667418 & S & 9455195 \\
& Córrego Mossoró II & E & 669002 & S & 9457410 \\
\hline \multirow{5}{*}{$06 / 06 / 2014$} & Passagem do Rio & E & 676331 & S & 9412516 \\
& Camurupim & E & 680582 & S & 9415182 \\
& Picada I & E & 680235 & S & 9418381 \\
& Picada II & E & 678478 & S & 9415206 \\
& São João da Várzea & E & 675738 & S & 9413299 \\
\hline
\end{tabular}

Numa avaliação qualitativa as águas se dividem em quatro classes de salinidade, à medida que aumenta a concentração de sais e, consequentemente, sua condutividade elétrica, recebendo denominações sucessivas de C1, C2, C3 e C4; esses limites apresentados por Richards (1954) são adotados como índices de salinidade:

C1 - Água de baixa salinidade. Pode ser usada para irrigação da maioria das culturas, em quase todos os tipos de solo, com muito pouca probabilidade de que se desenvolvam problemas de salinidade. Se necessária alguma lixiviação de sais, esta é conseguida em condições normais de irrigação, exceto em solos de muito baixa permeabilidade.

C2 - Água de média salinidade. Pode ser usada sempre que houver uma lixiviação moderada de sais. Em quase todos os casos se adequa ao cultivo de plantas moderadamente tolerante aos sais, sem necessidade de práticas especiais de controle de salinidade.

C3 - Água de alta salinidade. Não pode ser usada em solos com drenagem deficiente. Mesmo com drenagem adequada pode ser necessário práticas especiais de controle da salinidade, devendo, portanto, ser utilizada na irrigação de espécies vegetais de alta tolerância aos sais. Os riscos apresentados por esta classe de água podem ser amenizados quando do emprego do método de irrigação localizada mantendo o solo continuamente úmido.

C4 - Água de muito alta salinidade. Não é apropriada para irrigação sob condições normais, porém pode ser usada ocasionalmente, em circunstâncias muito especiais. Os solos devem ser permeáveis e a drenagem adequada, devendo ser aplicada água em excesso para se obter boa lixiviação de sais e, mesmo assim devem ser explorados com culturas altamente tolerantes aos sais.

A Relação de Adsorção de Sódio (RAS) é um índice que apresenta concentração relativa de sódio em relação às concentrações de $\mathrm{Ca}$ e $\mathrm{Mg}$ na solução ou no extrato de saturação, a qual é calculada a partir da seguinte equação:

$$
R A S=\frac{N a^{+}}{\left[\left(C a^{++}+M g^{++}\right) / 2\right]^{0,5}}
$$

Em que:

RAS é expressa em $\left(m m o l ~ L^{-1}\right)^{0,5}$ e as concentrações de $\mathrm{Na}$, Ca e $\mathrm{Mg}$, em mmol $_{\mathrm{c}} \mathrm{L}^{-1}$. 
Em cada comunidade foram coletadas amostras de três tipos de água: água do poço (AP); água dessalinizada (AD) e água de rejeito da dessalinização (AR).

As amostras foram acondicionadas em garrafas plásticas, opacas, de $500 \mathrm{ml}$, hermeticamente fechadas e conduzidas para análise laboratoriais. As análises foram realizadas em triplicata no Laboratório de Fertilidade e Nutrição de Plantas do Departamento de Ciências Ambientais e Tecnológicas, da Universidade Federal Rural do Semi-Árido (UFERSA).

Foram avaliados os parâmetros físico-químicos: condutividade elétrica (CE em dS m $\mathrm{m}^{-1}$ ), potencial hidrogeniônico $(\mathrm{pH})$, as concentrações de Sódio $\left(\mathrm{Na}^{+}\right)$, Cálcio $\left(\mathrm{Ca}^{2+}\right)$, Magnésio $\left(\mathrm{Mg}^{2+}\right)$, Potássio $\left(\mathrm{K}^{+}\right)$, Cloreto $\left(\mathrm{Cl}^{-}\right)$e dureza, de acordo com as metodologias propostas por Richards (1954) e EMBRAPA (1997).

Foi realizado o teste de Tukey de 1 a 5\% de probabilidade utilizando-se a estatística descritiva de todos os parâmetros analisados, com auxílio do software estatístico Assistat.

\section{Resultados e Discussão}

Verifica-se na Tabela 2, as análises das águas do poço (AP), dessalinizada (AD) e de rejeito (AR) com alguns parâmetros químicos que foram utilizados para a classificação dessas águas em relação à potabilidade e uso agrícola.

Tabela 2 - Características físico-químicas das amostras de água de poço, dessalinizada e rejeito da dessalinização, coletadas em onze comunidades rurais de Mossoró/RN.

\begin{tabular}{|c|c|c|c|c|c|c|c|c|c|c|}
\hline \multirow[b]{3}{*}{ Localidades } & \multirow[b]{3}{*}{ AM } & pH & $\mathrm{CE}$ & $\mathbf{K}^{+}$ & $\mathrm{Na}^{+}$ & $\mathbf{C a}^{2+}$ & $\mathbf{M g}^{2}$ & $\mathbf{C}^{\mathrm{l}^{-}}$ & RAS & \multirow{3}{*}{$\begin{array}{l}\text { Classificação } \\
\text { de Richards }\end{array}$} \\
\hline & & \multicolumn{3}{|c|}{$\mathrm{dS} \mathrm{m}^{-1}$} & \multirow{2}{*}{\multicolumn{2}{|c|}{$\mathrm{mmol} / \mathrm{L}$}} & & & & \\
\hline & & & & & & & & & & \\
\hline \multirow[t]{3}{*}{ Boa Fé } & $\mathrm{AD}$ & 7,22 & 0,32 & 0,06 & 1,98 & 0,19 & 0,25 & 2,80 & 4,2 & C2S1 \\
\hline & $\mathrm{AP}$ & 7,08 & 6,80 & 0,46 & 21,15 & 31,00 & 11,90 & 70,00 & 4,6 & C4S1 \\
\hline & AR & 7,43 & 6,95 & 0,57 & 24,67 & 28,75 & 20,00 & 80,00 & 5,0 & C4S1 \\
\hline \multirow[t]{3}{*}{ Puxa Boi } & $\mathrm{AD}$ & 7,92 & 0,11 & 0,08 & 5,94 & 3,00 & 1,50 & 10,00 & 4,0 & C1S1 \\
\hline & AP & 7,45 & 5,80 & 0,46 & 27,43 & 16,00 & 11,00 & 46,00 & 7,5 & C4S1 \\
\hline & AR & 7,34 & 5,65 & 0,33 & 24,09 & 17,50 & 11,00 & 51,00 & 6,4 & C4S1 \\
\hline \multirow[t]{3}{*}{ Oziel Alves } & $\mathrm{AD}$ & 7,69 & 0,37 & 0,01 & 1,31 & 0,40 & 0,61 & 2,60 & 1,8 & C2S1 \\
\hline & AP & 7,48 & 2,10 & 0,09 & 6,20 & 3,10 & 2,30 & 16,40 & 3,8 & C3S1 \\
\hline & $\mathrm{AR}$ & 7,30 & 2,55 & 0,09 & 6,51 & 3,34 & 3,05 & 18,40 & 3,6 & C4S1 \\
\hline \multirow[t]{3}{*}{ São Romão } & $\mathrm{AD}$ & 6,90 & 0,33 & 0,02 & 1,63 & 0,82 & 0,58 & 2,40 & 2,0 & C2S1 \\
\hline & AP & 7,32 & 2,33 & 0,12 & 10,17 & 8,95 & 3,15 & 16,00 & 4,1 & C4S1 \\
\hline & $\mathrm{AR}$ & 7,14 & 2,43 & 0,11 & 11,05 & 8,95 & 5,55 & 18,00 & 4,1 & C4S1 \\
\hline \multirow{3}{*}{$\begin{array}{l}\text { Córrego } \\
\text { Mossoró I }\end{array}$} & $\mathrm{AD}$ & 7,68 & 0,10 & 0,00 & 0,26 & 0,00 & 0,20 & 1,00 & 0,8 & C1S1 \\
\hline & $\mathrm{AP}$ & 7,23 & 1,40 & 0,06 & 2,77 & 3,00 & 2,06 & 8,00 & 1,7 & C3S1 \\
\hline & $\mathrm{AR}$ & 7,37 & 1,30 & 0,07 & 3,35 & 2,54 & 1,69 & 9,00 & 2,3 & C3S1 \\
\hline \multirow{3}{*}{$\begin{array}{l}\text { Córrego } \\
\text { Mossoró II }\end{array}$} & $\mathrm{AD}$ & 7,64 & 0,09 & 0,00 & 0,39 & 0,00 & 0,00 & 1,00 & 0,0 & C1 \\
\hline & AP & 7,24 & 1,90 & 0,13 & 4,75 & 3,38 & 2,04 & 12,80 & 2,9 & C3S1 \\
\hline & $\mathrm{AR}$ & 7,70 & 1,70 & 0,14 & 4,80 & 3,06 & 1,56 & 13,80 & 3,2 & C3S1 \\
\hline \multirow{3}{*}{$\begin{array}{l}\text { Passagem } \\
\text { do Rio }\end{array}$} & $\mathrm{AD}$ & 5,81 & 0,05 & 0,02 & 0,33 & 0,36 & 0,43 & 1,00 & 0,5 & C1S1 \\
\hline & AP & 6,85 & 2,66 & 0,03 & 8,80 & 7,99 & 5,81 & 21,00 & 3,4 & C4S1 \\
\hline & AR & 6,84 & 3,61 & 0,35 & 27,43 & 11,70 & 9,00 & 34,00 & 8,5 & C4S1 \\
\hline \multirow[t]{3}{*}{ Camurupim } & $\mathrm{AD}$ & 6,69 & 0,23 & 0,00 & 0,62 & 0,23 & 0,26 & 1,20 & 1,3 & C1S1 \\
\hline & AP & 7,34 & 4,63 & 0,26 & 4,23 & 14,60 & 13,90 & 39,00 & 1,1 & C4S1 \\
\hline & AR & 7,18 & 4,96 & 0,28 & 4,41 & 14,80 & 12,80 & 42,00 & 1,2 & C4S1 \\
\hline \multirow[t]{3}{*}{ Picada I } & $\mathrm{AD}$ & 6,55 & 0,16 & 0,01 & 0,71 & 0,42 & 0,30 & 1,00 & 1,2 & C1S1 \\
\hline & AP & 7,28 & 3,28 & 0,15 & 2,47 & 11,50 & 10,45 & 24,00 & 0,7 & C4S1 \\
\hline & $\mathrm{AR}$ & 7,67 & 3,87 & 0,20 & 3,00 & 12,30 & 12,10 & 30,00 & 0,9 & C4S1 \\
\hline
\end{tabular}


Tabela 2 - Características físico-químicas das amostras de água de poço, dessalinizada e rejeito da dessalinização, coletadas em onze comunidades rurais de Mossoró/RN.

\begin{tabular}{lcccccccccc} 
Picada II & AD & 7,32 & 0,40 & 0,01 & 0,71 & 0,27 & 0,20 & 1,00 & 1,5 & C2S1 \\
& AP & 7,48 & 2,49 & 0,14 & 1,95 & 8,60 & 10,00 & 14,00 & 0,6 & C4S1 \\
& AR & 7,38 & 3,00 & 0,16 & 3,26 & 9,00 & 10,30 & 15,00 & 1,1 & C4S1 \\
\hline São João & AD & 6,83 & 0,70 & 0,19 & 2,20 & 1,20 & 1,52 & 2,20 & 1,9 & C2S1 \\
da Várzea & AP & 7,27 & 1,48 & 0,38 & 3,67 & 4,30 & 7,80 & 4,20 & 1,5 & C3S1 \\
& AR & 7,28 & 1,50 & 0,37 & 3,87 & 4,95 & 8,35 & 4,80 & 1,5 & C3S1 \\
\hline
\end{tabular}

* $\mathrm{AM}$ = amostra, $\mathrm{AP}$ = água do poço, $\mathrm{AD}$ = água dessalinizada e $\mathrm{AR}=$ água de rejeito.

Observou-se que 63\% das águas de poços foram classificadas como C4S1 e as demais como C3S1. As águas classificadas como C4S1 possuem salinidade muito alta, não sendo apropriada para irrigação sob condições normais, porém pode ser usada ocasionalmente, em circunstâncias muito especiais. Os solos devem ser permeáveis, a drenagem adequada, devendo ser aplicada água em excesso para se obter uma boa lixiviação de sais e, mesmo assim devem ser explorados com culturas altamente tolerantes aos sais.

Verificou-se que 50\% das águas dessalinizadas são classificadas como C1S1 - baixo risco de salinidade e sodicidade e 50\% classificadas como C2S1 - médio risco de salinidade e baixo de sodicidade.

Os valores de $\mathrm{pH}$ da água dessalinizada durante o período experimental oscilaram de 5,81 a 7,92 , e valor médio $(7,11)$. Exceto para a comunidade de Passagem do Rio, o restante das amostras encontraram-se dentro da faixa de 6,0 a 9,5 estabelecido pela Portaria $n^{\circ}$ 2914/2011 (BRASIL, 2011) para potabilidade da água.

$\mathrm{O}$ valor médio de sódio $\left(1,46 \mathrm{mmol}_{\mathrm{c}} \mathrm{L}^{-1}\right)$, assim como os valores máximo e mínimo (5,94 e $0,26 \mathrm{mmol}_{\mathrm{c}} \mathrm{L}^{-1}$ ) encontrado na água dessalinizada foram inferiores ao limite de $8,7 \mathrm{mmol}_{\mathrm{c}} \mathrm{L}^{-1}$ estabelecido pela Portaria ${ }^{\circ}$ 2914/20011 (BRASIL, 2011), para potabilidade da água. Porém, para a comunidade Puxa Boi essa concentração encontrada é superior ao valor de $3,0 \mathrm{mmol}_{\mathrm{c}} \mathrm{L}^{-1}$ estabelecido por Ayers e Westcot (1999) para irrigação de cultivos agrícolas.

Das amostras de rejeito analisadas da Tabela 2, apresentaram 73\% de risco de salinização muito alto (C4S1), não sendo recomendados para irrigação em condições normais, podendo ser usada em condições especiais de solos com boa drenagem, desde que se aplique lâmina de lixiviação adequada, cultivos com plantas tolerantes aos efeitos dos sais da água. Os $27 \%$ restantes ficaram na classe C3S1 - risco alto de salinização que, segundo Gheyi et al. (2010) não pode ser usada em solos que tenham drenagem deficiente e, mesmo em solos com boa drenagem, pode necessitar de práticas especiais para controle da salinidade, principalmente ao uso de espécies de elevada tolerância à salinidade.

As águas dos rejeitos dos dessalinizadores mantiveram-se com as mesmas classificações que suas respectivas águas dos poços, apesar do aumento da CE para todas as amostras, com exceção da comunidade de Oziel Alves, que apresentou rejeito classificado em C4 (Tabela 2).

Com relação à condutividade elétrica das águas dos poços, observou-se na Figura 2 que os maiores valores ocorreram nas comunidades de Boa Fé, Puxa Boi, Picada I e Camurupim, com valores de 6,80; 5,80 e 4,63 e 3,28 dS m${ }^{-1}$ respectivamente, apresentando severas restrições de uso (CE > 3,0 $\mathrm{dS} \mathrm{m}^{-1}$ ), de acordo com as diretrizes propostas por Ayres e Westcot (1999). As águas dos poços das demais comunidades têm moderadas restrições de uso quanto aos riscos de salinidade $(0,7$ - 3,0 dS m $\left.{ }^{1}\right)$.

A condutividade elétrica média $\left(0,26 \mathrm{dS} \mathrm{\textrm {m } ^ { - 1 } )}\right.$ da água dessalinizada e os valores máximo e mínimo ( 0,70 e $\left.0,05 \mathrm{dS} \mathrm{m}^{-1}\right)$ atenderam ao padrão de potabilidade da água, sendo seu valor médio encontrado inferior ao limite de 1,57 dS $\mathrm{m}^{-1}$ estabelecido pela Portaria $\mathrm{n}^{0}$ 2914/20011 (BRASIL, 2011).

Consequentemente, os rejeitos dos mesmos sistemas apresentaram os maiores valores de condutividade, 6,95 dS m $\mathrm{m}^{-1}$ para a comunidade de Boa Fé; 5,65 dS m $\mathrm{m}^{-1}$ para comunidade de Puxa Boi; 4,96 dS m $\mathrm{m}^{-1}$ para a comunidade de Camurupim e $3,87 \mathrm{dS} \mathrm{m}^{-1}$ para a comunidade de Picada I. A 
condutividade elétrica média da água do poço, da água dessalinizada e do rejeito de todos os sistemas analisados foi de 3,17, 0,26 e 3,41 dS $\mathrm{m}^{-1}$, respectivamente.

Figura 2 - Condutividade elétrica $\left(\mathrm{dS} \mathrm{m}^{-1}\right)$ da água dos poços, da água do rejeito e da água dessalinizada de todos os sistemas avaliados.

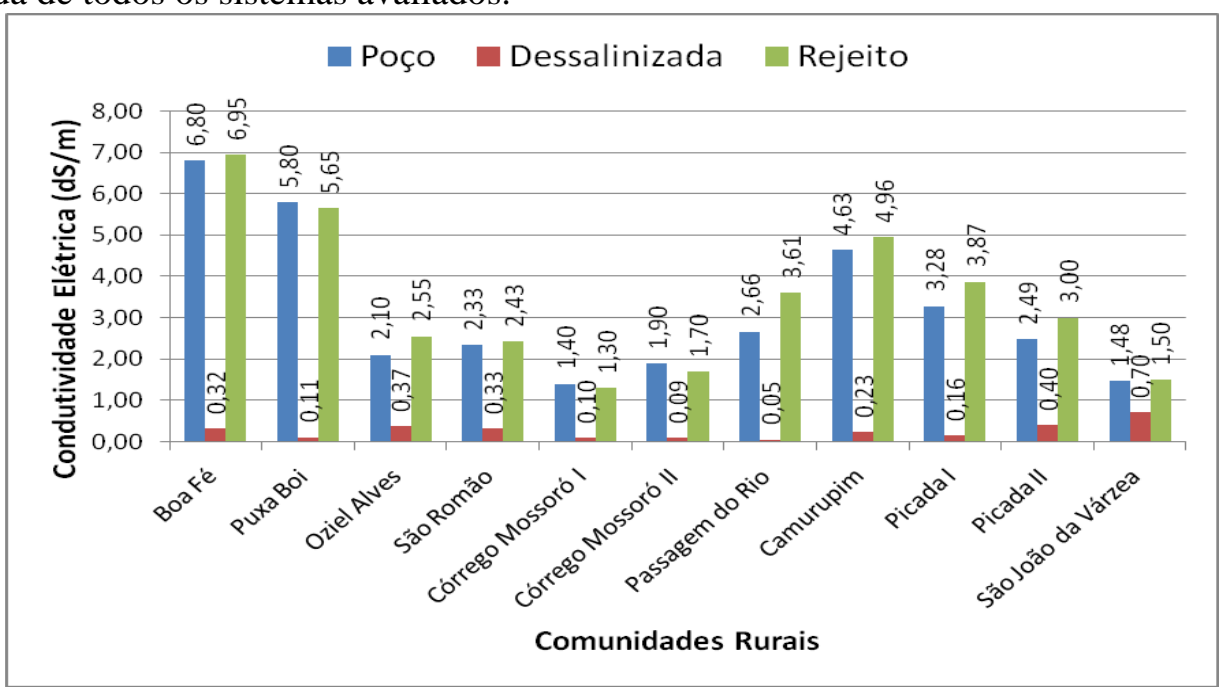

Na análise dos íons, observaram-se na Figura 3 e na Tabela 2 os valores médios em mmol/L dos cátions e ânions das águas dos poços, dos rejeitos e das águas dessalinizadas dos sistemas de dessalinização avaliados. Verificou-se que os íons de maior presença nas águas dos poços foram o sódio, cálcio, magnésio e o cloreto, podendo, os mesmos, também serem quantificados na água do rejeito e na água dessalinizada.

Figura 3 - Valores médios em mmol/L, dos íons das águas dos poços, dos rejeitos e das águas dessalinizadas dos sistemas de dessalinização avaliados.

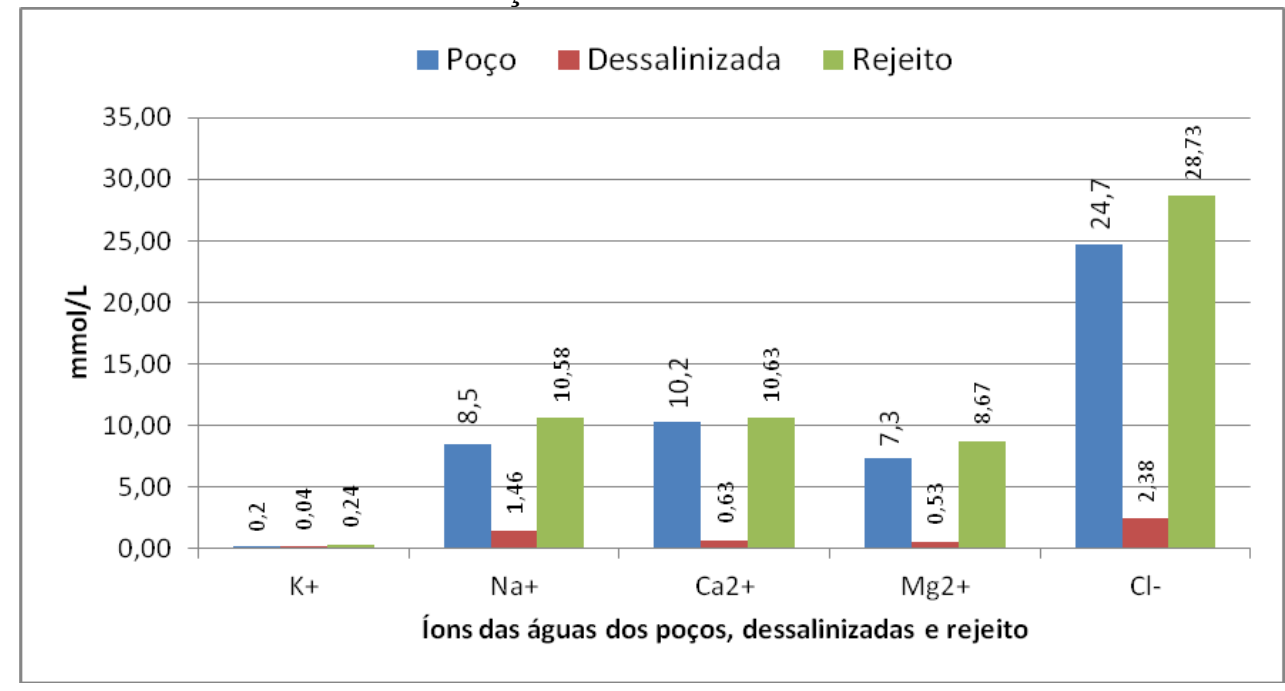

Os teores de $\mathrm{Na}$, Ca e $\mathrm{Mg}$ das águas de poço e de rejeito são elevados (Figura 3), o que contribuiu para os altos níveis de salinidades destas águas. Estes níveis elevados de sais podem contribuir para a salinidade dos solos, quando são depositados de forma incorreta diretamente no solo ou em corpos superficiais de água.

O rejeito salino tem restrições de uso para fins de irrigação quando manejado inadequadamente e, a sua deposição direta nos solos provoca a salinização das áreas das comunidades, agravando o processo de desertificação. Riley et al. (1997) consideraram o cultivo de plantas halófitas a melhor opção para dispor o rejeito da osmose reversa. Conforme Glenn et al. (1998), a halófita Atriplex nummularia tem atributos desejáveis de uma cultura cicladora de rejeito: alto uso consuntivo da água 
para maximizar a absorção, alta tolerância aos sais para minimizar a fração de lixiviação requerida e elevada produtividade de biomassa, a qual tem utilidade forrageira.

De acordo com as diretrizes propostas por Ayers e Westcot (1999), verifica-se que, quanto aos riscos de toxidez, $81 \%$ das águas de poços tem grau de restrição de uso severo para cloreto $\left(\mathrm{Cl}^{-}>9\right.$ mmolc $\mathrm{L}^{-1}$ ) e $19 \%$ com severas restrições de uso para irrigação.

Com relação à toxidez por excesso de sódio, a água das comunidades de Boa Fé Puxa Boi e São Romão tem grau de restrição de uso severo, em $45 \%$ das comunidades foi observada moderada restrições de uso e $27 \%$ não apresentaram restrição de uso.

De uma maneira geral, a eficiência dos dessalinizadores das comunidades estudadas é elevada, a remoção dos íons $\mathrm{K}^{+}, \mathrm{Na}^{+}, \mathrm{Ca}^{2+}, \mathrm{Mg}^{2+}$ e $\mathrm{Cl}^{-}$foi de 82,6, 82,8, 93,9, 92,72 e 90\%, respectivamente, para a condutividade elétrica a remoção foi de $92 \%$.

Em relação ao padrão de potabilidade para a dureza da água, observou-se que o valor médio da dureza (63,7 mg/L), bem como os valores máximo e mínimo (225 e $10 \mathrm{mg} / \mathrm{L}$ ) encontrados na água dessalinizada foram inferiores ao limite de $500 \mathrm{mg} / \mathrm{L}$ estabelecido pela Portaria $\mathrm{n}^{\circ}$ 2914/2011 (BRASIL, 2011), para potabilidade da água. Assim, dependendo da concentração, a água passa a ser classificada como água branda (0 - $40 \mathrm{mg} / \mathrm{L})$, água moderada $(40-100 \mathrm{mg} / \mathrm{L})$, água dura (100 - 300 $\mathrm{mg} / \mathrm{L}$ ), água muito dura (300 - $500 \mathrm{mg} / \mathrm{L}$ ) e água extremamente dura (com teores acima de $500 \mathrm{mg} / \mathrm{L}$ ). Analisando os dados na Figura 4, verificou-se que as águas de poços como as de rejeito, são classificadas em água dura à extremamente dura. Enquanto que, nas águas dessalinizadas foi observada, em geral, água branda, com exceção da comunidade Oziel e São Romão que apresentou água moderada, e as comunidades Puxa Boi e São João da Várzea que se notou águas duras.

Figura 4 - Valores de dureza das amostras de água coletadas nas comunidades rurais de Mossoró/RN.

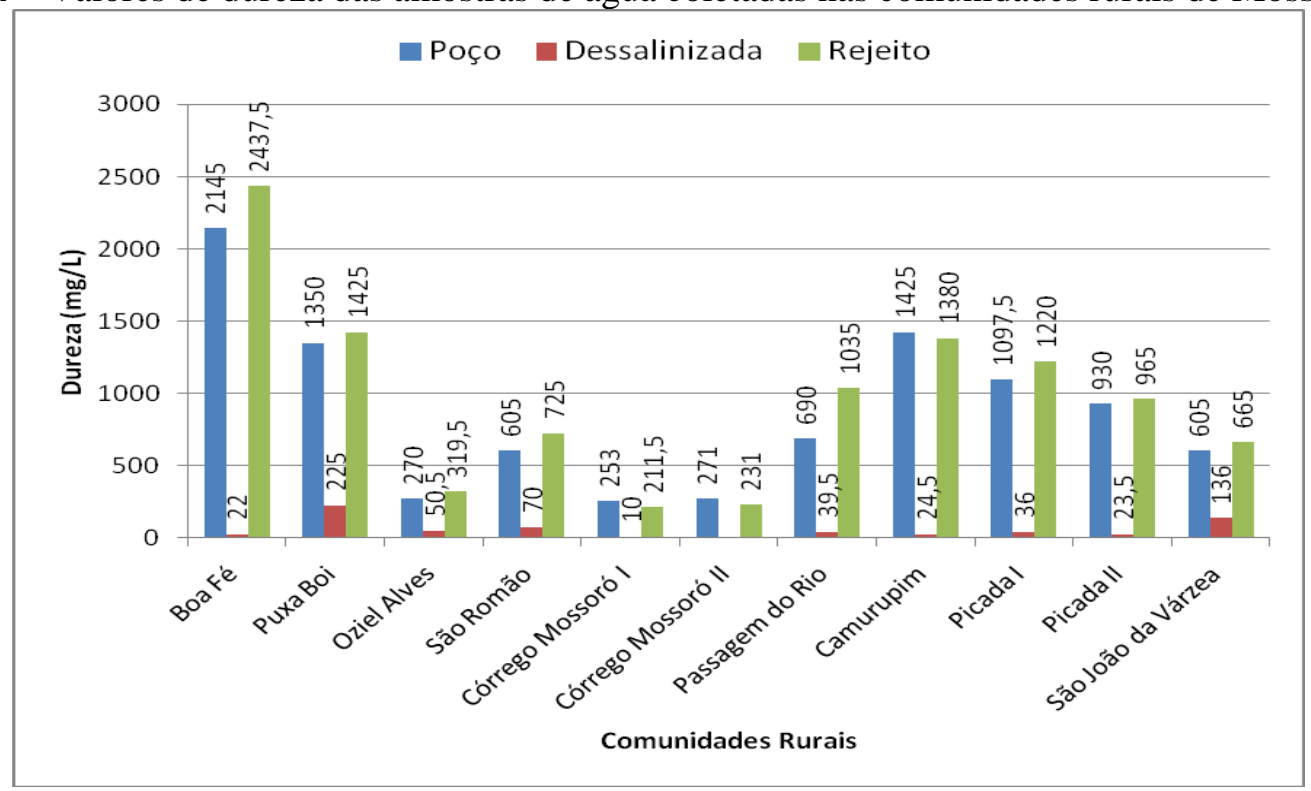

\section{Conclusões}

De um modo geral, as instalações dos equipamentos de dessalinização trouxeram um enorme ganho na qualidade de vida das comunidades, pelo fato de representar uma ferramenta eficaz no fornecimento regular de água doce no período de estiagem do semiárido.

As águas retiradas diretamente dos dessalinizadores apresentaram qualidades satisfatórias, quanto à remoção de íons, o que comprova sua eficiência na redução da salinidade. Contudo, não foi possível determinar o impacto exato desta melhoria na saúde da população estudada, devido à ausência em análises que comprovassem a isenção de uma contaminação bacteriológica.

Os dados obtidos apontam que as águas dos poços e as águas de rejeito das comunidades rurais estudadas possuem restrições para a sua utilização na agricultura, por apresentarem elevadas concentrações de sais, favorecendo riscos de salinização e sodificação do solo. 


\title{
Water Quality Desalinated I ntended to Rural Communities of Mossoró/ RN
}

\begin{abstract}
:
The scarcity of water, both in quantity and in quality, in northeastern Brazil, triggers concussion in socioeconomic development and even the survival of the population.

The objective of this study was to evaluate the quality of water for the rural communities of Natal, supplied with brackish water from wells, equipped with desalination plants. This study was conducted in 11 rural communities in the municipality of Mossoró/RN, which were installed stations brackish water treatments by good design and drinking water of the federal and state governments. In each community were collected samples of three types of water: well water (AP); desalinated water (AD) and reject the desalination of water (AR). The physical and chemical parameters evaluated were: electrical conductivity $\left(\mathrm{EC}\right.$ in $\left.\mathrm{dS} \mathrm{m}^{-1}\right)$, hydrogenic potential $(\mathrm{pH})$, the sodium $\left(\mathrm{Na}^{+}\right)$, calcium $\left(\mathrm{Ca}^{2+}\right)$, magnesium $\left(\mathrm{Mg}^{2+}\right)$, Potassium $\left(\mathrm{K}^{+}\right)$, chloride $\left(\mathrm{Cl}^{-}\right)$and hardness, according to the methodology proposed by Richards (1954) and EMBRAPA (1997). There was, in general, the facilities of desalination equipment brought an enormous gain in quality of life in communities, because it represents an effective tool in the regular supply of fresh water in the dry season the semiarid region. Taken directly from the water desalination plants showed satisfactory qualities, as the removal of ions, which proves its effectiveness in reducing salinity. However, it was not possible to determine the exact impact of this improvement in the health of this population due to the absence of tests proving that the exemption of bacteriological contamination. The data obtained show that the waters of the wells and the waste of water studied rural communities have restrictions for their use in agriculture, because they have high concentrations of salts, favoring risk of salinization and soil sodification.:
\end{abstract}

Keywords: Water scarcity; desalination; physicochemical parameters.

\section{Referências Bibliográficas}

AMORIM, M. C. C. de; PORTO, E. R.; MATOS, A. N. B.; SILVA, D. F. da. Diagnóstico de sistemas de dessalinização de água salobra subterrânea em municípios do estado da Paraíba-Brasil. In: CONGRESSO BRASILEIRO DE ÁGUAS SUBTERRÂNEAS, 13, 2004, Cuiabá, MT. Anais... Cuiabá: ABAS, 2004. CD-ROM.

ANDERS, C. R. Caracterização química da água de dessalinizadores e dos solos sob a influência do rejeito salino em Mossoró- RN. 2013. 53p. Dissertação (Mestrado em Ciência dos Solos) Universidade Federal Rural do Semi-Árido (UFERSA). Mossoró, RN, 2013.

AYERS, R. S.; WESTCOT, D. W. A qualidade da água na agricultura. Campina Grande: UFPB, 153p, 1999. (Estudos FAO - Irrigação e Drenagem, 29).

BRASIL. Ministério da Saúde. Secretaria de Vigilância em Saúde. Portaria $\mathbf{n}^{0}$. 2.914, de 12 de dezembro de 2011. Dispõe sobre os procedimentos de controle e de vigilância da qualidade da água para consumo humano e seu padrão de potabilidade. Diário Oficial da União. Poder Executivo, Brasília, DF, 2011.

CARMO FILHO, F.; OLIVEIRA, O. F. Mossoró: um município do semiárido nordestino, caracterização climática e aspecto florístico. Mossoró: ESAM, 62p, 1995. (Coleção Mossoroense, Série B). 
COSME, C. R. Avaliação da qualidade da água proveniente das estações de tratamento de água salobra na zona rural do município de Mossoró-RN. Dissertação (Mestrado em Irrigação e Drenagem) Universidade Federal Rural do Semiárido, 2011.

CPRM - SERVIÇO GEOLÓGICO DO BRASIL. Projeto cadastro de fontes de abastecimento por água subterrânea. Diagnóstico do município de Mossoró, estado do Rio Grande do Norte. 11p. 2005. Disponível em: http://www.cprm.gov.br/rehi/atlas/rgnorte/relatorios/MOSS089.PDF. Acesso em 10 de julho 2014.

EMPRESA BRASILEIRA DE PESQUISA AGROPECUÁRIA - EMBRAPA. Manual de métodos de análise de solos. Rio de Janeiro, 212p, 1997.

GHEYI, H. R.; DIAS, N. S.; LACERDA, C. F. L . Manejo da Salinidade na agricultura: estudos básicos e aplicados. Fortaleza-CE: INCT SAL, 470p, 2010.

GLENN, E. P; THOMPSON, T. L.; MIYAMOTO, S. Halophyte crops and a sand-bed solar concentrator to reduce and recycle industrial, desalination and agricultural brines. Tucson: United States Department of the Interior. 78p. 1998. Desalination Research and Development Program Report N. 35.

NETO, F. L.; P., OLIVEIRA, J. H. de. Programa de dessalinizadores de água para pequenas comunidades - posto de atendimento eletrônico. In: CONGRESSO BRASILEIRO DE ENGENHARIA SANITÁRIA E AMBIENTAL, 19, 2007, Belo Horizonte, MG. Anais... Belo Horizonte: ABES, 2007. CD-ROM.

PORTO, E. R.; AMORIM, M. C. C. de; SILVA JUNIOR, L. G. A. Uso do rejeito de dessalinização de água salobra para irrigação da erva-sal (Atriplex nummularia). Revista Brasileira da Engenharia Agrícola e Ambiental, Campina Grande, v. 5, n. 1, 111-114p. 2001.

REBOUÇAS, A. C. Água doce no mundo e no Brasil. In: REBOUÇAS, A. C.; BRAGA, B; TUNDISI, J G. (Ed.). Águas doces no Brasil: capital ecológico, uso e conservação. São Paulo: Escrituras, 1999.

RICHARDS, L.A. (ed.). Diagnosis and improvement of saline and alkali soils. Washington D.C.: U.S. Salinity Labratory, 160p, 1954. (USDA. Agriculture Handbook, 60).

RILEY, J. J.; FITZSIMMONS, K. M.; GLENN, E. P. Halophyte irrigation: an overlooked strategy for management of membrane fraction concentrate. Desalination, Amsterdam, v.110, n.3, 197-21p. 1997.

SOARES, TALES M.; SILVA, IRAN J. O. da; DUARTE, SERGIO N.; SILVA, ÊNIO F. DE F. E. Destinação de águas residuárias provenientes do processo de dessalinização por osmose reversa. Revista Brasileira de Engenharia Agrícola e Ambiental, v.10, n.3, 730-737p. 2006. 